University of Wollongong

Research Online

Faculty of Business - Papers (Archive)

Faculty of Business and Law

$1-1-2013$

The CAPM: Theoretical Validity, Empirical Intractability and Practical

Applications

Philip Brown

University of New South Wales

Terry S. Walter

University of Technology Sydney, twalter@uow.edu.au

Follow this and additional works at: https://ro.uow.edu.au/buspapers

Part of the Business Commons

Research Online is the open access institutional repository for the University of Wollongong. For further information contact the UOW Library: research-pubs@uow.edu.au 


\title{
The CAPM: Theoretical Validity, Empirical Intractability and Practical Applications
}

\author{
Abstract \\ The capital asset pricing model (CAPM) is an ex ante concept, whereas so-called 'tests' of the CAPM are \\ conducted ex post.The CAPM is a partial equilibrium model in which agents view the risk-free return (Rf) \\ and the probability distribution of the future return on risky assets (Rj) as exogenous. Dempsey (2013) \\ argues that the empirical evidence against the CAPM is so compelling that it has reached the point where \\ the CAPM should be abandoned, possibly being replaced by an assumption that investors expect the \\ same return on all assets, regardless of their relative risk. \\ Disciplines \\ Business \\ Publication Details \\ Brown, P. \& Walter, T. (2013). The CAPM: Theoretical Validity, Empirical Intractability and Practical \\ Applications. Abacus: a journal of accounting, finance and business studies, 49 (SUPPL.1), 44-50.
}


The CAPM: Theoretical Validity, Empirical Intractability and Practical Applications

Philip Brown ${ }^{1}$ and Terry Walter ${ }^{2}$

1. UWA Business School, The University of Western Australia, and School of Accounting, Australian School of Business, The University of New South Wales

2. School of Finance, UTS Business School, University of Technology, Sydney, and UWA Business School, The University of Western Australia

ABSTRACT

Dempsey (2011) argues that the empirical evidence against the CAPM is so compelling that the CAPM should be abandoned, perhaps in favour of the assumption of the same expected return on all assets. There are two problems with this argument. First, it presumes the evidence is valid. Thirtyfive years ago Richard Roll (1977) concluded that the so-called "tests" of the CAPM were invalid because they used inefficient benchmark portfolios, whereas a valid test of the CAPM requires that the benchmark be efficient. Second, the suggestion that investors do not differentiate investment opportunities according to their unavoidable risk runs counter to the beliefs of theorists and practitioners and cannot be taken seriously. Finance practitioners and researchers continue, justifiably, to believe ex ante risk matters and that a risk premium exists, even if ex post their belief defies empirical confirmation. Dempsey's message is not new: beta, which is at the heart of the CAPM, has been declared dead more than once, yet the CAPM, in one or other of its various guises, lives on. 


\section{Introduction}

The capital asset pricing model (CAPM) is an ex ante concept, whereas so-called "tests" of the CAPM are conducted ex post. The CAPM is a partial equilibrium model in which agents view the risk-free return $\left(R_{f}\right)$ and the probability distribution of the future return on risky assets $(\tilde{R} j)$ as exogenous. Dempsey (2011) argues that the empirical evidence against the CAPM is sufficiently compelling that it has reached the point where the CAPM should be abandoned possibly being replaced by an assumption that investors expect the same return on all assets. There are two problems with this argument. First, it presumes the evidence is valid. Thirty-five years ago Richard Roll (1977) concluded that the so-called "tests" of the CAPM were invalid because they used inefficient benchmark portfolios, whereas a valid test of the CAPM requires that the benchmark be efficient. Second, the suggestion that investors do not differentiate investment opportunities according to their unavoidable risk runs counter to the beliefs of theorists and practitioners and cannot be taken seriously. Finance practitioners and researchers continue, justifiably, to believe ex ante risk matters and that a risk premium exists, even if ex post their belief defies empirical confirmation. Further to the first point, there remains a long debate on the validity of the evidence; see in particular Roll (1977), Roll and Ross (1994), Kandel and Stambaugh (1995), Jagannathan and Wang (1996), Feldman (2007) and Diacogiannis and Feldman (2011). These papers argue that the empirical evidence on the CAPM has been incorrectly interpreted because it is of questionable validity. In relation to the second point, we assert finance practitioners and researchers are not acting like lemmings or flat earthists when they believe that risk matters and that a risk premium exists. Many continue to use the CAPM, perhaps because of the elegance of its intellectual parentage (i.e., Markowitz (1952, 1959) - for which Harry Markowitz received the jointly awarded 1990 Nobel Prize in Economics). At various times beta has been declared dead (see Fama and French (1992)), yet perhaps like some of Albert Einstein's theories which are proving extremely difficult to test (he received the 1921 Nobel Prize for Physics), the CAPM also remains unverified. For that reason we hold onto the concept that unavoidable investment risk is priced because a viable alternative idea has not been found.

\section{Building Blocks of Modern Finance Theory}

According to Jensen and Smith (1984) the fundamental building blocks for the modern theory of financial economics are, in rough chronological order, efficient market theory (EMT), portfolio theory, capital asset pricing theory (CAPT), option pricing theory, and agency theory. Dempsey (2011) discusses EMT and CAPT in some detail. The precursor to the development of CAPT, namely portfolio theory developed by Markowitz $(1952,1959)$ is not mentioned. Neither does Dempsey mention Roll's (1977) critique of tests of the CAPM.

\section{Portfolio Theory of Harry Markowitz $(1952,1959)$}

Markowitz $(1952,1959)$ advanced a theory to explain the benefits of diversification, and gave us an explanation for the widely observed behaviour that most investors "prefer not to put all their eggs in one basket". He showed that, in the context of a diversified portfolio, the risk of an individual investment when added to a portfolio depends not on the variance of the individual investment's returns (which was previously regarded as an appropriate measure of risk) but on the extent to which adding that investment would change the risk of the whole portfolio. The total risk of a portfolio comprising $\mathrm{N}$ individual investments contains $\mathrm{N}^{2}$ covariance terms, of which $\mathrm{N}$ are usually referred to as variances. As $\mathrm{N}$ becomes large, the number of covariance terms dominates the 
variance terms. For example, the variance of a portfolio comprising 50 stocks has 2,450 covariance terms (or $98 \%$ of all terms that collectively determine the risk of the portfolio) and only 50 individual stock variances. Markowitz (1952) did not provide any detail on how best to estimate these future covariances, but commented that "the observed (values) for some period of the past" might be used. He added that he believed that "what is needed is essentially a "probabilistic" reformulation of security analysis". His 1952 paper noted that "there are techniques by which we can compute the set of efficient $(E, V)^{1}$ combinations" but rather than present those methods he "illustrate(d) geometrically the nature of the efficient surfaces for cases in which $\mathrm{N}$ (the number of securities) is small”. Figure 1 from Markowitz (1952) is reproduced below, on the left.
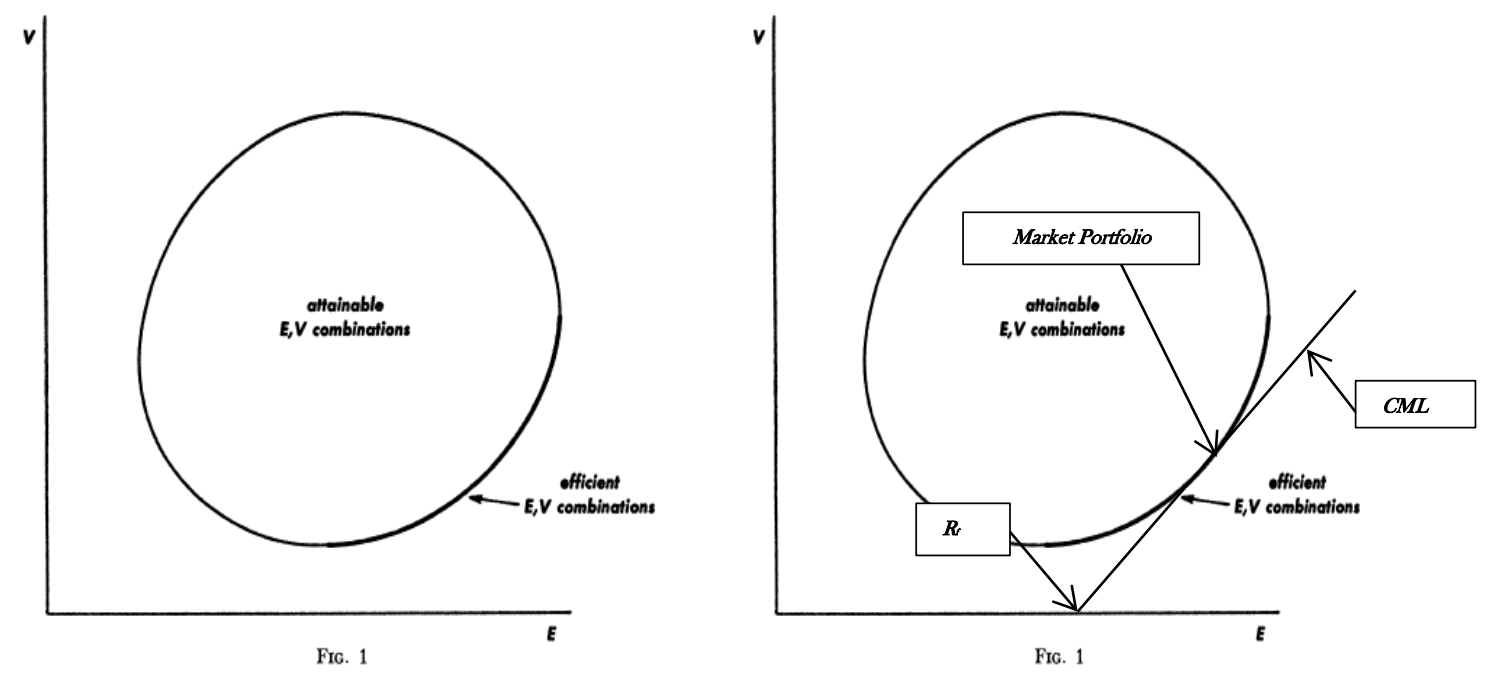

While subsequent developments in asset pricing generally have displayed expected return on the vertical axis, it is not difficult to envisage the capital asset pricing model in Markowitz's figure. If it is assumed that investors can borrow or lend unlimited amounts at a riskless rate of interest $\left(R_{f}\right)$ then we can imagine a straight line from $R_{f}$ that is tangential to the efficient $E, V$ combinations. This line is the capital market line $(C M L)$, and is shown as modifications to the original figure on the right.

Markowitz's contribution to the modern theory of finance has not been challenged. It was acknowledged when he was jointly awarded the 1990 Nobel Prize in Economics "for having developed the theory of portfolio choice". It is worth noting that the 1990 Nobel Prize in Economics was jointly awarded to Harry Markowitz, William Sharpe and Merton Miller: Sharpe "for his contributions to the theory of price formation for financial assets, the so-called, Capital Asset Pricing Model (CAPM)" and Miller "for his fundamental contributions to the theory of corporate finance".

Suppose the portfolio being considered is the "market portfolio" (rather than the more limited efficient $E, V$ combinations in Markowitz (1952)). In principle the market portfolio comprises all assets in the global economy, each having a weight equal to its contribution to the total value of all assets. While this is a highly abstract notion, in such a theoretically perfectly diversified portfolio the variance of any individual asset makes essentially no contribution to the portfolio variance, but its

\footnotetext{
${ }^{1} E$ is the expected return on a portfolio of securities and $V$ is the variance of the portfolio returns.
} 
covariance with the other assets in the portfolio may be of some consequence. This is the fundamental building block of CAPT: it is covariance risk that matters, since variance risk is essentially eliminated in a well-diversified portfolio.

While the fundamental insight of portfolio theory remains unchallenged, implementation in a strict sense is not practical, ${ }^{2}$ because to build an efficient portfolio for a particular investor we need to know the expected returns, expected variances and expected covariances of all possible candidates for inclusion in the portfolio. And even if that were possible, the individual's risk preferences are likely to change over time. Nevertheless, portfolio theory tells us that covariance risk matters more than variance risk in determining the risk of the portfolio. And of course the average covariance of an asset's return with the market portfolio is its CAPM beta. Thus development of the CAPM allowed the insights of Markowitz's $(1952,1959)$ to be simplified. The simple elegance of portfolio theory caused a paradigmatic shift in how risk is perceived and it is thus not surprising that several researchers expanded on Markowitz's insights in more or less simultaneous development of CAPT. Several versions emerged, including those of Tobin (1958), Treynor (1961), Sharpe (1964), Lintner (1965), and Mossin (1966).

These developments spawned a large empirical literature that supposedly "tested" the predictions of the CAPM. Many of these papers are summarised in Sections 2 and 3 of Dempsey (2011) and we will not critique them. However, Roll's (1977) paper, and several subsequent papers - in particular Roll and Ross (1994), Kandel and Stambaugh (1995), Jagannathan and Wang (1996), Feldman (2007) and Diacogiannis and Feldman (2011) - showed that the CAPM could not be tested unless "the true market portfolio's composition" is known.

\section{Roll's (1977) Critique of Tests of Asset Pricing Theory}

Roll (1977) showed that, while testing two-parameter asset pricing theory is possible in principle, "no correct and unambiguous test of the theory has appeared in the literature" to that time and that "there is practically no possibility that such a test can be accomplished in the future". These propositions are still valid today. Much of Dempsey's Sections 2 and 3 amounts to a critique of previous "tests" of asset pricing, which Roll had done more than 30 years earlier. However Dempsey is far from alone in this respect. As Diacogiannis and Feldman (2011, p.5) note, "it is not clear that ... the essential implication - that linear beta pricing with efficient benchmark regressions (LBPE) with inefficient benchmarks are meaningless - has been sufficiently internalized".

Roll (1977) established that "there is only a single testable hypothesis associated with the generalized two-parameter asset pricing model of Black (1972). This hypothesis is: 'the market portfolio is mean-variance efficient'"'. Several related conclusions were drawn, some of which are summarised below:

- The best known so-called implication of the CAPM, that beta is linearly related to expected return, is not independently testable.

- Asset pricing theory is not testable unless the exact composition of the true market portfolio is known and used in the tests.

\footnotetext{
${ }^{2}$ Markowitz called this the "second stage in the process of selecting a portfolio" (1952, p.91).
} 
- Using a proxy for the market portfolio has two difficulties. First, the proxy might be mean-variance efficient even when the true market portfolio is not. Alternatively, the proxy might be inefficient, and cannot be used to test the efficiency of the true market portfolio.

Has financial economics simply ignored Roll (1977)? The answer is "No"; however the attempts to accommodate Roll's critique that we briefly describe below are flawed. First, Campbell et al. (1997) discuss several approaches ${ }^{3}$ to consider if inferences about the empirical validity of the CAPM are sensitive to the use of a broad index of equity returns, in lieu of the true market portfolio. These approaches suggest that Roll's concern is: (i) a valid theoretical concern, but not an empirical problem (Stambaugh, 1982); or (ii) lessened, provided that the correlation between the proxy and the true market portfolio exceeds 0.70 , in which case acceptance/rejection of the CAPM with a market proxy implies acceptance/rejection of the CAPM with the true market portfolio. Empirical research has thus continued. But this research is based on an assumption, typically implicit, that the proxy used in the tests (typically, a broad index of listed equities such as the S\&P 500 or the ASX200) is highly correlated with the true market portfolio. It is surprising that relatively little has been done (Stambaugh (1982) is an exception) to establish the historical returns for a broader set of internationally diversified assets including both listed and unlisted equities, government and private debt, real estate, natural resources, art, precious metals, and so on. Now here's the rub: crucially, Diacogiannis and Feldman (2011, p. 28) note "that it is meaningless to use inefficient benchmarks to implement regressions of CAPM, which is designed to use efficient benchmarks". They show that "the adverse effects of using inefficient benchmarks in a model for efficient ones ... occur for all inefficient benchmarks regardless of their "distance" from the (efficient) frontier". Attempts to "fix" empirical tests of the CAPM, are in short, fundamentally flawed because the exact composition of the true market portfolio is not and may never be known.

\section{Practical Evidence of the CAPM's Continued Relevance}

The CAPM, which is an ex ante concept, is used widely by corporations in their capital budgeting and capital structure decisions, and by academics when considering adjustments for differences in risk.

\section{Corporations use the CAPM in capital budgeting}

Graham and Harvey (2001) surveyed the CFOs of 392 US firms and found that large firms rely heavily on present value techniques and the CAPM in their capital budgeting, while small firms are more likely to use a payback method. The CAPM was used always or almost always by $73.5 \%$ of respondents when estimating the cost of capital. Graham and Harvey (2005) reported quarterly estimates by US CFOs made between June 2000 and June 2005 of the 10-year market risk premium over 10 -year US Treasury Bonds. The average 10 -year bold yield was $4.6 \%$, and the average market risk premium was $3.7 \%$.

\section{Regulatory agencies use the CAPM in price setting}

The CAPM has become the "industry standard" for regulatory decisions on the cost of capital and price determination for utilities (see Romano (2005) for US and Grayburn et al. (2002) for UK evidence). Gray and Hall $(2006,2008)$ refer to more than ten Australian bodies that regulate

\footnotetext{
${ }^{3}$ See for example Stambaugh (1982), Kandel and Stambaugh (1987) and Shanken (1987).
} 
infrastructure assets, worth more than $\$ A 100 \mathrm{bn}$ in total, where those assets were acquired after evaluation using CAPM-derived cost of capital estimates.

\section{Market efficiency tests recognize they are joint tests}

Tests of market efficiency have, since Fama's $(1970,1991)$ review articles, recognised that they involve a joint hypothesis test: that (i) the market is efficient and (ii) the correct model describing the expected return on an asset has been specified. Fama (1991) poses the question of whether the joint-hypothesis problem makes empirical work on asset-pricing models uninteresting. His answer is "an unequivocal no". He states (1991, p. 1576) "The empirical literature on efficiency and assetpricing models passes the acid test of scientific usefulness. It has changed our views about the behaviour of returns, across securities and through time ... The empirical work on market efficiency and asset-pricing models has also changed the views and practices of market professionals". We accept his judgment.

\section{Academics and practitioners continue to estimate $R m-R f$, and to use the CAPM in teaching corporate finance}

Fernandez et al. (2011b) reports survey results for academics' and practitioners' estimates of the market risk premium. Estimates are provided for 56 countries, with the largest number of responses coming from the US (1503 responses) and Spain (930). The mean ex ante market risk premium for the US is $5.5 \%$ with a standard deviation of $1.7 \%$, while the mean Spanish estimate is $5.9 \%(1.6 \%$ standard deviation). The mean estimate for Australia is 5.9\% (1.9\% standard deviation). Similar surveys have been conducted previously, with US premiums being estimated by academics at $6.3 \%$, $6.4 \%, 6.0 \%$ and $5.7 \%$ in 2008, 2009, 2010 and 2011 respectively (Fernandez et al., 2011a). Brealey et al. (2011) is one of the most widely used textbooks in corporate finance classes. While the FamaFrench three factor model and APT are mentioned, Brealey et al. (2011) and Ross et al. (2010) advocate that the CAPM be used to estimate the expected cost of capital.

\section{Conclusions}

It is worth reiterating that the CAPM is fundamentally an ex ante concept that provides us with a way of thinking about risk in the context of an efficiently diversified portfolio of investments.

Dempsey (2011) argues that the empirical evidence against the CAPM is sufficiently compelling that it has reached the point where the CAPM should be abandoned, perhaps being replaced by an assumption that investors expect the same return on all assets. There are two problems with this argument. First, it presumes the evidence is valid. However, valid tests of the CAPM require efficient benchmarks, which so far have proven elusive. Second, the idea that investors do not expect to be compensated for avoidable risk is inconsistent with the beliefs of theorists and practitioners, namely that risk matters such that, ex ante, a risk premium must exist. Researchers and practitioners continue to use the CAPM, perhaps because of the elegance of its intellectual parentage. At various times beta, at the heart of the CAPM, has been declared dead; nonetheless the CAPM, being extremely difficult if not impossible to test, lives on.

PB: the second last sentence might be better stated as "the idea that investors expect to be compensated for unavoidable risk" 
I have left et al. in italics as this seems to be Abacus style. 


\section{References}

Black, F., 'Capital Market Equilibrium with Restricted Borrowing', The Journal of Business, Vol. 45, No. 3, 1972.

Brealey, R., Myers, S. and F. Allen, Principles of Corporate Finance, McGraw-Hill/Irwin, New York, N.Y., 2011.

Campbell, J., Lo, A. and A. MacKinley, The Econometrics of Financial Markets, Princeton University Press, Princeton, N.J., 1997.

Dempsey, M., 'The Capital Asset Pricing Model (CAPM): The History of a Failed Revolutionary Idea in Finance?', Abacus, this issue 2011.

Diacogiannis, G. and D. Feldman, 'Linear Beta Pricing with Inefficient Benchmarks', Working paper, Australian School of Business, The University of New South Wales, 2011.

Fama, E., 'Efficient Capital Markets: A Review of Theory and Empirical Work', The Journal of Finance, Vol. 25, No. 2, 1970.

Fama, E., 'Efficient Capital Markets: II', The Journal of Finance, Vol. 46, No. 5, 1991.

Fama, E. and K. French, 'The Cross-Section of Expected Stock Returns', The Journal of Finance, Vol. 47, No. 2, 1992.

Feldman, D., 'Incomplete Information Equilibria: Separation Theorems and Other Myths', Annals of Operations Research, Vol. 151, No. 1, 2007.

Fernandez, P., Aguirreamalloa, J. and L. Corres, 'Market Risk Premiums used in 56 Countries in 2011: A Survey with 6,014 Answers', Unpublished manuscript, IESE Business School, Madrid, 2011a.

Fernandez, P., Aguirreamalloa, J. and L. Corres, 'US Market Risk Premium used in 2011 by Professors, Analysts and Companies: A Survey with 5,731 Answers', Unpublished manuscript, IESE Business School, Madrid, 2011b.

Graham, J. R. and C. R. Harvey, 'The Long-Run Equity Risk Premium', Finance Research Letters, Vol. 2, 2005.

Graham, J. R. and C. R. Harvey, 'The Theory and Practice of Corporate Finance: Evidence from the Field', Journal of Financial Economics, Vol. 60, No. 2-3, 2001.

Gray, S. and J. Hall, 'Relationship between Franking Credits and the Market Risk Premium', Accounting and Finance, Vol. 46, No. 3, 2006.

Gray, S. and J. Hall, 'Relationship between Franking Credits and the Market Risk Premium: A Reply', Accounting and Finance, Vol. 48, No. 1, 2008.

Grayburn, J., Hern, R. and H. Lay, A Report for the National Audit Office on Regulatory Risk, National Audit Office, U.K., 2002. 
Jagannathan, R. and Z. Wang, 'The Conditional CAPM and the Cross-Section of Expected Returns', The Journal of Finance, Vol. 51, No. 1, 1996.

Jensen, M. and C. Smith, 'The Theory of Corporate Finance: A Historical Overview', in The Modern Theory of Corporate Finance, M. Jensen and C. Smith, Editors. McGraw-Hill Inc., New York, 1984.

Kandel, S. and R. F. Stambaugh, 'On Correlations and Inferences about Mean-Variance Efficiency', Journal of Financial Economics, Vol. 18, No. 1, 1987.

Kandel, S. and R. F. Stambaugh, 'Portfolio Inefficiency and the Cross-Section of Expected Returns, The Journal of Finance, Vol. 50, No. 1, 1995.

Lintner, J., 'The Valuation of Risk Assets and the Selection of Risky Investments in Stock Portfolios and Capital Budgets', The Review of Economics and Statistics, Vol. 47, No. 1, 1965.

Markowitz, H., 'Portfolio Selection', The Journal of Finance, Vol. 7, No. 1, 1952.

Markowitz, H., Portfolio Selection, Efficient Diversification of Investments, John Wiley and Sons, Inc., New York, 1959.

Mossin, J., 'Equilibrium in a Capital Asset Market', Econometrica, Vol. 34, No. 4, 1966.

Roll, R., 'A Critique of the Asset Pricing Theory's Tests', Journal of Financial Economics, Vol. 4, No. 2, 1977.

Roll, R and S. A. Ross, 'On the Cross-Sectional Relation between Expected Returns and Betas', The Journal of Finance, Vol. 49, No. 1, 1994.

Romano, R., 'After the Revolution in Corporate Law', Journal of Legal Education, Vol. 55, 2005.

Ross, S. A., Westerfield, R. W. and J. Jaffe, Corporate Finance, The McGraw Hill Companies, Inc., New York, 2010.

Shanken, J., 'Multivariate Proxies and Asset Pricing Relations: Living with the Roll Critique', Journal of Financial Economics, Vol. 18, No. 1, 1987.

Sharpe, W., 'Capital Asset Prices: A Theory of Market Equilibrium under Conditions of Risk', The Journal of Finance, Vol. 19, No. 3, 1964.

Stambaugh, R., 'On the Exclusion of Assets from Tests of the Two Parameter Model', Journal of Financial Economics, Vol. 10, No. 3, 1982.

Tobin, J., 'Liquidity Preference as Behavior Towards Risk', Review of Economic Studies, Vol. 25, No. 2, 1958.

Treynor, J. L., 'Toward a theory of market value of risky assets', Mimeo, subsequently published in R. A. Korajczyk (ed.) (1999) Asset Pricing and Portfolios Performance: Models, Strategy and Performance Metrics, Risk Books, London, 1961. 